\title{
The impact of the federal funds rate on an investor's return
}

\author{
Ikhlaas Gurrib a* \\ a School of Graduate Studies at the Canadian University of Dubai, United Arab Emirates. \\ ${ }^{*}$ Corresponding author's email address: ikhlaas@cud.ac.ae
}

\section{H I G H L I G H T S:}

1. The paper looks at the effect of changes in the Federal Funds Rate on both the U.S. (domestic market) Market returns and the Dubai Financial Market (international market) returns.

2. Changes in the monthly S\&P500 and DFM market indices data and changes in the FFR rates are used in regression models.

3. To account for the effect of monetary policy reversals on market returns, a dummy variable is integrated together with the changes in FFR rates variable, in both pre and post financial settings.

4. Results suggest that chosen international market is highly sensitive to the change in FFR compared to domestic market.

5. As part of robustness testing, both the S\&P500 Index and DFM Index are found to be significantly affected by positive changes in the FFR, where the effect tend to be more negative on the international market returns.

\section{Article History $\quad$ A B S T R A C T}

Received: 11-12-2014

Accepted: 24-01-2015

Available online: 26-02-2015

Keywords:

Federal funds rate;

Pre and post financial crisis.

JEL Classification:

E44; F36; G15.
Market index returns;

The study aims to analyze stock price movements of the world's widely used index S\&P 500 and the rapid growing economy index of Dubai Financial Market (DFM). While UAE adopts a similar monetary policy to the US due to the pegging of the two countries' currencies, UAE's GDP and financial markets have been witnessing more robust performance since the financial crisis, raising the issue as to whether following monetary policy actions set by the Federal Reserve Bank is beneficial to the UAE financial markets. The paper investigates the effect of changes in Federal Funds Rate (FFR) on the domestic U.S. market returns studied through S\&P 500 and the international UAE DFM market returns observed through DFM index. The models under analysis not only look at the effect of changes in the FFR on market indices' returns, but also whether U.S. monetary policy reversals have a stronger effect than other changes, by imposing a dummy variable adjustment to the model. As part of robustness testing, further analysis is carried out by defragmenting the data into the pre and post financial crisis of 2008. Findings suggest that the DFM index is highly sensitive to the change in FFR compared to S\&P 500 index. Compared to the pre financial crisis, both the S\&P500 Index and DFM Index are significantly affected by positive changes in the FFR. Positive changes in the FFR tend to affect the DFM returns more negatively than S\&P500 Returns, suggesting any future positive change in FFR would affect the financial markets negatively, by pulling prices down globally.

DOI: http://dx.doi.org/10.18533/jefs.v3i01.152

(C) 2015 The Authors. This is an open access article under the terms of the Creative Commons Attribution License 4.0, which allows use, distribution and reproduction in any medium, provided the original work is properly cited.

\subsection{Introduction}

Stock markets are volatile in nature and there are many factors that affect the stock prices including global events, performance of companies, new acquisitions, change in policies, changes in interest rates, among others. These events or changes may lead to an increase in some stocks' market values and decrease in others, where the net effect can be proxied through changes in a stock market index, which is a basket of different securities or stocks. 
Any state which is interested in trading establishes such stock market indices comprised of different securities and are monitored under the financial markets regulatory boards or commissions such as the Securities Exchange Commission in the US and the Securities and Commodities Authority in the UAE (Grouard, Levy and Lubochinsky, 2003). The S\&P 500 Index, a holding of the top 500 companies in the U.S. and the Dubai Financial Market Index (DFM) of the UAE have been chosen as the stock market indices for this study due to the U.S. being one of the major markets controlling the global financial market and the UAE being one of the rapid pace growing economies to have recently been included in the MSCI Emerging Market Index. More importantly, with the UAE currency (dirham) being fixed to the US dollar, this results in the Central Bank of UAE inability to adopt an independent monetary policy approach. Alternatively stated, the low interest rates in the US are often mirrored in the UAE as well. The critical policy issue arises due to both countries sharing different economic outlooks with the UAE's GDP being much more robust that the developed economy's one. With a limited use of monetary policy options, the UAE policy makers are left mostly with macro- prudential regulation tools to control excess credit growth and lending for instance. To this end, the paper provides some highlights to whether adopting foreign monetary policy led by the US leads bears some significant relationships to the DFM market in terms of capital gains or losses. Further, the benchmarking of the findings with the US provides further information as to whether international markets are being affected more by foreign policy actions set by the Federal Reserve Bank. For instance, will the reduction in the highly accommodative interest policy set in the US have policy implications for the domestic and foreign financial markets, where such markets are usually reflecting the any possible effect, contagion or not, on an economy.

With changes happening across the globe and the ever present imposition of globalization, any event across any economy could have a global impact. The dotcom bubble of 2000 and real estate bubble of 2008 caused major financial dilemmas across the globe and have affected many economies, indicating that there is some dependency on the global market returns and factors that get affected due to such events. How U.S. monetary policy changes affect the financial markets in general and stock returns in particular in other countries than the home country is of interest for global financial stability and international portfolio management. For instance, Elyasiani and Mansur (2003) argue that the development and wide application of telecommunication technology, globalization of business activities, increased policy and regulatory coordination among the central governments are likely to reinforce the interdependence of banking sectors across countries. Other studies like Sweeney and Warga (1986), Tai (2000), Flannery and James (1984) and Bae (1990) decomposed interest rate changes into unexpected and expected components and linked those changes to stock returns in the banking sector. The methodologies found in existing literature to define and construct interest rate changes series and their relationships with indices or stock returns vary quite extensively, resulting in varying degrees of conclusive remarks.

Generally speaking, the Federal Funds Rate (FFR), which is set by the Federal Open Market Committee (FOMC), is the rate of interest at which federal funds are traded among the depository institutions. Federal funds are the balances held at the Federal Reserve by the participating depository institutions. It is defined as the rate of interest at which commercial banks lend money from their federal funds to other banks and is determined from the difference of demand for funds and supply of funds. The rate fluctuates depending on the position of the supply of funds from commercial banks and the demand for loans by other banks. FFR is applied when banks lend to other banks, while if banks borrow money for themselves then a discount window as applied by Central bank is levied. Such a discount window is called the discount rate, repo rate, or base rate but not federal funds rate (Koba, 2012). In that line of thought, Madura and Zarruk (1995) show that interest rate risk is lesser for US banks compared to their international counterparties. Simiarly, while Craine and Martin (2008) found that US unexpected yields affects Australian stock indices and bond yields, Faff and Howard (1999) find that Australian banking stocks tend to be more sensitive to interest rate changes, with varying stability sensitivitiveness over different periods.

The FFR affects both the monetary and financial conditions, which leads to other impacts on wider issues such as employment, inflation, dollar value, bank loans and growth. The link between these issues can be explained as; when the FFR is high, this means that banks will cut down on borrowing reserves since they will be charged high er rates. To generate more money, they will increase interest rates which will have a direct influence on the spending of both individuals and companies as their expenditure will be cut down or reduced. Another influence of reducing the expenditure is that producers will lower their prices to reduce the excess in supply, which will decrease the inflation rates and increase unemployment level as companies want to decrease their costs (Effective Federal Funds Rate, 2014). FFR is subject to changes as per the decisions made by FOMC and the board. In general, with the global economic performance and position, the board varies the FFR. Changes in FFR are made so that the Federal bank can support the banks and financial institutions, which can further support the improvement of the economy and balance the position without any discrepancies. Figure 1 clearly indicates that from 2000 , the rate has fallen down very steeply. The financial crisis of 2000 due to dotcom bubble has severely hit many banks and financial institutions (FI) forcing the Central Bank to reduce the FFR to support the banks/FI to cope up with the situation. By 2003, with the economy recovering, the FFR has started to rise back till 2008. With the real estate bubble, the 
economy has again been hit more severely with the financial crisis and FFR has been steeply reduced to values below $1 \%$. This has been maintained since then, helping the banks/ FI to recover.

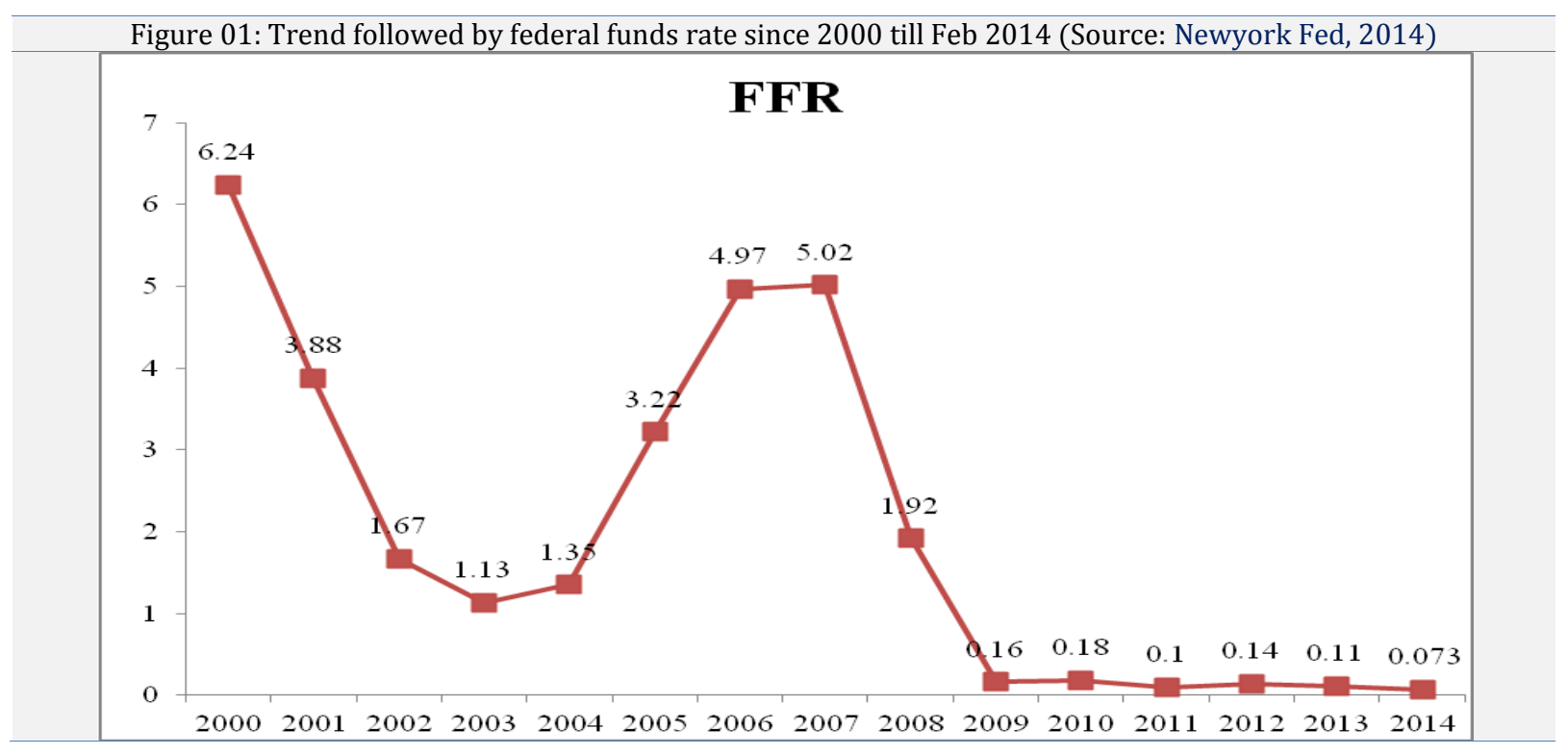

Banks/FI are the main institutions that were badly hit due to the real estate bubble as they were the prime lending institutions and have mortgaged many properties as securities. Thus, the FOMC has decided to reduce the FFR to support the banking institutions and has been monitoring the rates to fix them accordingly to improve the global scenario. The current FFR, as of $25^{\text {th }}$ March 2014, is at 0.09 with a target rate of $0.25 \%$ (Newyork Fed, 2014). Janet Yellen, the new Chairman of the Federal Reserve (FED) has indicated the possibility of raising federal funds rate after a two day meeting of FOMC. Subsequently, the FOMC announced that the monetary policy remains unchanged and no longer is the FFR considered based on unemployment rate in isolation. Factors including labor market, inflation rate and financial developments also would be taken into account while defining the FFR. As understood from the announcement, if the FFR increases, it would be first time over 8 years that FFR would see an increase and would also change its target range category (Mahn, 2014).

\subsection{Effect of FFR change in S\&P 500 index and DFM index}

The increase in FFR indicates that banks offer loans to other banks at higher interest rates, thereby increasing normal interest rate on loans, and vice versa. In general, FFR acts as an indicator of monetary policy that is closely monitored by the investors in the stock markets. Garg and Chapman (2008) showed that not all sectors are equally affected due to changes in FFR. They noted that financial services, telecommunications sector and basic utilities/ materials sectors are the most sensitive sectors to the movement of FFR. Bernanke and Kuttner (2005) performed an extensive analysis on how the equity prices have been affected by the impact of monetary policy changes and found financial markets are the most directly affected due to monetary changes. Thorton (2000) found that the market returns are strongly dependent on the FFR risk post-financial crisis as they lead to changes in the interest rates, monetary policies and inflation rates of the economy, which are closely scrutinized by the investors. Hegwood and Tuttle (2013) found a long run relationship between FFR and mortgage interest rate during 2002 and 2005. Taibbi (2010) supported Greenspan to be a major enabler of the bubble economy and financial crisis, where the latter claimed that the rates' relationship broke down since mortgage interest rates failed to respond as expected to the Fed tightening policy in the mid-2004. Figure 2 shows the S\&P 500 Index and the FFR over the 1957-2014 period. The left hand axis represents the index values, while the right hand provides the FFR rates in per cent. As shown by the linear line, FFR has been trending downwards. A closer look shows that the market index values of S\&P 500 during 2000 to 2002 have been decreasing when the FFR was decreasing. From 2003 to 2008, as the FFR increases, the index values have also increased. From 2008, the FFR has witnessed a steep decrease where the value of S\&P 500 dropped as well. The direct relationship between FFR and the S\&P500 Index however lost momentum post early 2009 where the two variables moved in opposite directions. Figure 3 shows the DFM Index and the FFR movements over the 2010-2014 periods. The right hand axis represents the index values, while the left hand provides the FFR rates in per cent. The DFM Index tended to follow a positive trend while the FFR has been trending downwards. 

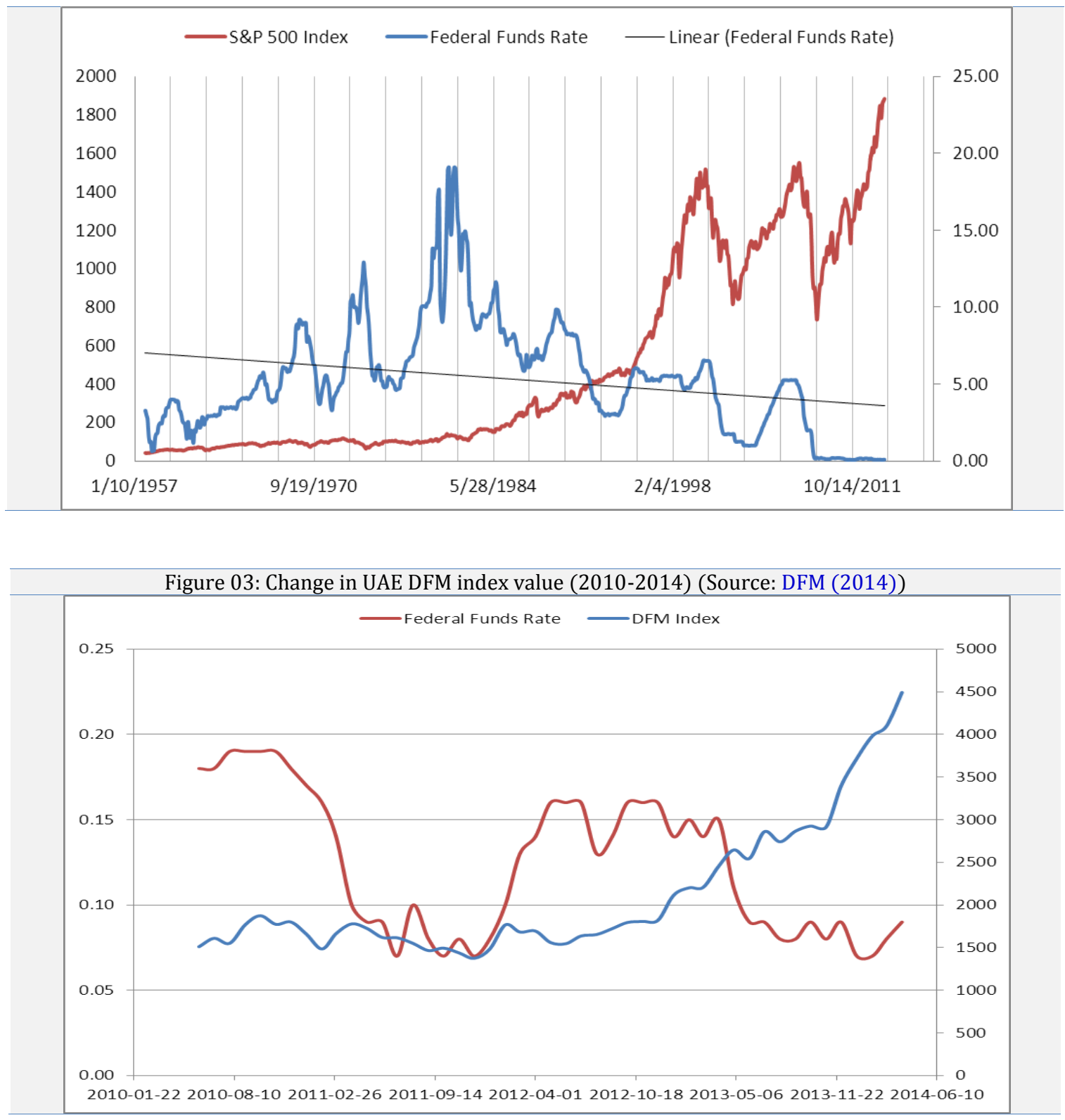

Although a graphical representation about the relation between the indices' price movements and the FFR changes is conceivable at times, further analysis can be done accurately by establishing a model that relates the FFR rates with the stock market values. For the purpose of this study, the discounted cash flow model is used as a framework.

This model is used in finance to state the value of an asset and represents the asset value as the present value of expected future cash flows that are derived by that specific asset. There are two ways in which the monetary policy affects the value of an asset. The first way includes changes in the future cash flows; when the FFR target increases due to contractionary monetary policy, expected future cash flows will eventually decrease. On the other hand, when monetary policy is tightened and there is an increase in the expected future cash flows' discounts factors, it is expected that the value of the asset will decrease (Yin and Yang, 2013). Elyasiani and Mansur (2003) found many factors support the interdependence in all banking sectors across many countries including globalization of business activities, the spread of telecommunication technology, and the increase in different policies and regulations coordination among the central governments. To this end, the purpose of this study is to analyze the effect of changes in the FFR on both the U.S. market (domestic market) and the DFM market returns. The rest of the paper provides the data collection and analysis, together with some robustness testing, before ending with some conclusive remarks.

\subsection{Data and research methodology}

This paper will explain the effect of changes in FFR on both the US S\&P 500 index return and GCC DFM index return. Datastream and Yahoo Finance have been used as a source for collection of historical data of S\&P 500 index. The DFM data is collected from the home site of Dubai Financial Markets. Since the DFM was established only in 2000 and recognized for trading since 2005, the historical data of the index is only available from 2007. Monthly FFR 
data has been obtained from the Federal Statistics Bureau. The current Federal target rate is between 0 to $0.25 \%$. The data has been cross checked with the data used in the existing literature and also Mubasher Trading Systems, which provide live trading data platform to both individual and institutions.

The returns can be estimated using the daily closing index value of the S\&P 500 and DFM indices. The daily returns are calculated using the difference between today's market index at close and yesterday's market index at close, and are reported in percentages. The average of all the daily returns on a monthly basis is computed to obtain the average monthly return. It can be observed that the highest annual return of the S\&P 500 index was observed in the year 2011 at 0.005 . The lowest return was in the month of October in 2008 with a rate of -0.0068 . Due to the financial crisis, it can be noted that there is sudden steep fall in the DFM index returns after 2007, and it has been falling continuously till 2011. The highest return for the DFM was noted in October 2007 with a rate 0.0247 , while the lowest was in November 2008 with a rate of -0.0227 . It can be observed that both S\&P 500 and DFM returns showed the lowest rates in the year 2008, as different economies around the world were hit severely because of the financial crisis (MSCI, 2012).

\section{$2.01 \quad$ FFR model}

To test for the relationship between changes in FFR and indices' returns, the following model of FFR is used in determining the relationship.

Return $_{t}=\pi+\beta$ Changein FFR $+\varepsilon_{t}$

This model is similar to the Capital Asset Pricing Model used to analyze the market risk and return where return expected from a security is given by the risk free rate and beta times the market risk premium. In general, it is understood that a higher risk premium would be compensated with a higher return, and vice versa, indicating a positive linear relationship between the risk and return (Fama and French, 2004). Similarly, the model in this study indicates that the return on index is directly related to the change in FFR. It is controlled by the fixed minimum market return defined by the intercept. The slope defines the relationship with the FFR which is meas ured by the beta and it measures the sensitivity of the returns on the index to changes in the FFR. The regression results are provided with the relevant coefficient and $p$-values in Table 1.

\begin{tabular}{lrrrr}
\hline \multicolumn{4}{c}{ Table 01: Relationship between index returns and FFR changes } \\
\hline \multicolumn{4}{c}{ US Market } & UAE Market \\
\hline & Coefficients & P-value & Coefficients & P-value \\
Intercept $(\Pi)$ & 0.000148368 & 0.3599966 & 0.001306132 & 0.139905312 \\
Change in FFR $(\beta)$ & 0.000284216 & 0.4222142 & 0.010282544 & 0.038217947 \\
\hline
\end{tabular}

Findings suggest the relationship between the returns of S\&P 500 and changes in the FFR are positive. If the FFR value increases, the returns of S\&P 500 index increases by 0.00028 times the change in FFR. However, this model is found to be valid only for $0.38 \%$ as defined by the $\mathrm{R}^{2}$ value, suggesting that only $0.38 \%$ of the S\&P 500 index is explained by the changes in the FFR. The significance of the independent variable is measured by the $p$-value, which tests that the null hypothesis that the coefficient is equal to zero. The $p$-value is much higher than the confidence level of 0.05 and hence null hypothesis that there is no significant impact of change in FFR on the returns of S\&P 500 is accepted. It is also noticeable that the relationship between the returns of DFM and changes in the FFR is positive. If the FFR value increases, the return of the DFM index increases by 0.0103 times the change in FFR. The model shows a validity of $5 \%$ only as defined by the $\mathrm{R}^{2}$ value in the regression analysis. This indicates that only $5 \%$ of the DFM index is explained by the changes in the FFR. The $p$-value was found to be 0.0382 in this case. A $p$ value of 0.0382 means that there is a nearly $4 \%$ chance that the relationship emerged randomly between the change in the FFR and DFM returns, inferring a significant impact of changes in FFR on the international DFM average monthly returns. As discussed above, it can be noted that the change in FFR would bring a change in returns of S\&P 500 index by 0.00028 times while it would bring a change of 0.01028 times in the DFM market index. It can be understood that the change in returns of DFM index is high compared to change in returns of S\&P 500 index per unit change in FFR. Since the beta value of S\&P 500 index is smaller than the beta value of DFM index this indicates that the DFM index is more sensitive to the change in FFR rates. The findings are consistent to Garg and Chapman (2008), who carried a sector wide analysis and found a positive relationship between the FFR and the US sector indices.

\subsection{Impact of policy reversals}

Policy reversals occur when a contractionary policy is changed to an expansionary policy or vice versa. Since FFR and monetary policy variables such as interest rates share significant relationships, a policy reversal will affect the FFR and possibly affect index market returns. This can be explained by the fact that the Fed seldom reverses a 
monetary policy immediately after a new direction is started. The market tends to interpret the first target change in a new direction as the first of a series of target changes in the same direction, thus extracting a more pronounced market reaction (Yin and Yang, 2013). Therefore, it can be noted that the first change in the FFR being a positive or negative also has a significant impact on the returns of the market. A refined model, which includes a dummy variable, is proposed as follows:

Return $_{t}=\pi+\beta$ Changein FFR $+\gamma$.Dummy.ChangeinFFR $+\varepsilon_{t}$

The dummy variable represents the effect of a positive change of FFR on index returns. It is 1 if there is a positive change in FFR and 0 if there is a negative change in FFR. This model shows more pronounced market reaction with higher returns in case of a positive change in FFR or else, it would remain unchanged as the previous model. The regression result is provided in Table 2 . For any positive change in FFR, substituting Dummy $=1$ in the above equation, the refined model defined above would change into:

\begin{tabular}{|c|c|c|c|c|}
\hline \multicolumn{5}{|c|}{ Table 02: Refined relationship between index returns and FFR changes } \\
\hline & & US Market & & UAE Market \\
\hline & Coefficients & P-value & Coefficients & P-value \\
\hline Intercept (П) & 0.000332794 & 0.0591372 & 0.000319583 & 0.747178156 \\
\hline Change in FFR $(\beta)$ & 0.002666254 & 0.0088604 & 0.007657544 & 0.126795428 \\
\hline Refined FFR $(\gamma)$ & -0.002773372 & 0.0126259 & 0.146373267 & 0.045555662 \\
\hline
\end{tabular}

Findings suggest the relationship between the return of S\&P 500 index and changes in the FFR is positive. If the FFR value increases, the return of S\&P 500 index increases by 0.00267 times the change in FFR. On the other hand, there is a negative relationship between the return of S\&P 500 and the refined FFR when there is a positive change in the FFR. Results provides validity of $4 \%$ only as defined by the $\mathrm{R}^{2}$ value, indicating that only $4 \%$ of the S\&P 500 index is explained by the changes in the FFR and refined FFR. The low $p$-value of 0.0089 means that there is a $0.8 \%$ chance that the relationship emerged randomly between the change in the FFR and S\&P 500 return. The refined FFR has a $p$-value of 0.0126 that is higher than the $p$-value of the change in FFR, but also considered significant as both values are much lesser compared to the significance level at 0.05 inferring rejection of null hypothesis. This suggests that the change in returns of domestic market as indicated by S\&P 500 index is significantly impacted to positive changes in FFR. Table 2 also supports that the relationships between the return of DFM Index and changes in the FFR, including the refined FFR, are positive. If the FFR value increases, the return of DFM index increases by 0.00766 times the change in FFR. On the other hand, an increase in refined FFR value will lead to an increase in the return of DFM index by 0.14637 times the in refined FFR. The low value of $\mathrm{R}^{2}$ indicates that only $9.6 \%$ of the DFM index is explained by the changes in the FFR and refined FFR. A $p$-value of 0.1268 means that the changes in FFR are not associated with changes in the return. While the other variable that is the refined FFR has a $p$-value of 0.0456 that is lower than the $p$-value of the change in FFR, suggesting a strong statistical impulse to reject the null hypothesis. The $p$-values based on the change in FFR alone could not be rejected but due to refined FFR is rejected. This implies that the market returns of international market as indicated by DFM index is not significantly impacted due to changes in FFR, although positive changes in the FFR tend to mildly affect the index returns on their own.

\subsection{Robustness testing: Pre and post financial crisis}

The world economy was severely affected during the period of 2008, with the real estate bubble hit in the U.S. and the major banks like Lehman brothers going bankrupt. There are many policy changes and interest rate reductions that have taken place to support all institutions and banks to recover from the crisis. FFR also had decreased from 2008 onwards and has attracted investors due to the lower rates availability. The market returns also started to fall down in the early 2008 with the decrease in the FFR and then slowly recovering with the pace of growth (Yin and Yang, 2013). As part of robustness testing, the previous FFR models used in this study are analyzed by breaking the data into pre and post financial crisis data. For the scope of this paper and data constraints, pre financial crisis data is gathered for the 2000 - September 2008, while post financial crisis consists of September 2008 to 2014 . Lehman Brothers filed for bankruptcy on the $15^{\text {th }}$ September 2008 and political chaos that followed was that it led to the most significant real-economy disaster of the post war era (Economist, 2013).

\subsubsection{Standard model}

Pre-financial crisis 
Due to data availability, S\&P 500 index data is analyzed for the whole period defined above but DFM index is only available from 2007 onwards due to its inception in 2007. Thus, for DFM pre-financial crisis period, only one year data from 2007 to Sep 2008 has been analyzed. Applying regression on the index returns and the FFR changes, the results can be viewed in Table 3 .

Table 03: Relationship between index returns and FFR changes (Pre financial crisis)

\begin{tabular}{lrrrr}
\multicolumn{5}{c}{ Table 03: Relationship between index returns and FFR changes (Pre financial crisis) } \\
\hline & US Market & UAE Market \\
\hline & Coefficients & P-value & Coefficients & P-value \\
Intercept $(\Pi)$ & $-0.0001 \%$ & $99.4532 \%$ & $0.0616 \%$ & $82.0150 \%$ \\
Change in FFR $(\beta)$ & $0.0081 \%$ & $80.3769 \%$ & $-0.5097 \%$ & $57.9152 \%$ \\
\hline
\end{tabular}

It can be noted from Table 3 that the relationship is positive where if the FFR value increases, the returns of S\&P 500 index increases by 0.00008 times the change in FFR. Alpha is negative, suggesting that the expected value on the return will be less than zero, when the changes in FFR variables are set to zero. The low value of $\mathrm{R}^{2}$ indicates that only $0.06 \%$ of the S\&P 500 index is explained by the changes in the FFR. It was also found that the $p$-value is 0.804, which is significantly high, and above 0.05 inferring that there is no significant impact of changes in FFR on the domestic market returns as indicated by the S\&P 500 index. It can be noted that the relationship between FFR and the DFM index returns is negative where the increase in FFR value will decrease the returns of DFM index by 0.0051 times the change in FFR. This model is found to be valid only for $1.9 \%$ as defined by the $\mathrm{R}^{2}$ value, indicating that only $1.9 \%$ of the DFM index is explained by the changes in the FFR. This rate indicates a very low relationship between the two variables. It was also found that the $p$-value is 0.579 , suggesting that changes in FFR are not associated with changes in return.

\section{Post financial crisis}

As discussed and defined above, post financial crisis is defined as the period after September 2008 till date. The regression results are provided in Table 4.

\begin{tabular}{lrrrr}
\hline \multicolumn{4}{|c}{ Table 04: Relationship between index returns and FFR changes (Post financial crisis) } \\
\hline & US Market & UAE Market \\
\hline & Coefficients & P-value & Coefficients & P-value \\
\hline Intercept (П) & $0.0381 \%$ & $18.4253 \%$ & $0.0295 \%$ & $74.9256 \%$ \\
Change in FFR ( $\beta)$ & $0.1679 \%$ & $10.7963 \%$ & $0.2302 \%$ & $49.3147 \%$ \\
\hline
\end{tabular}

It can be noted that following the inception financial crisis date of September 2008, S\&P 500 index returns shared a positive relationship with the change in FFR. Any positive increase in FFR will increase the index returns by 0.00168 . The $\mathrm{R}^{2}$ value of $3.8 \%$ indicates that the S\&P 500 index is hardly explained by the changes in the FFR. Similarly, it was also found that the $p$-value is 0.108 , suggesting that changes in FFR are not associated with changes in return. Further, it can be observed that, DFM has maintained its positive relationship with the FFR. Any positive increase in FFR led to an increase in index returns and vice versa. The value of $\mathrm{R}^{2}$ indicates that only $0.7 \%$ of the DFM index is explained by the changes in the FFR. The high $p$-value suggests that changes in FFR are not associated with changes in return.

\subsubsection{Refined model}

\section{Pre-financial crisis}

For the refined model, a dummy variable is assigned and defined as 1 if change in FFR is positive and otherwise zero. The findings of the refined model in the pre financial crisis period can be found in Table 5 .

\begin{tabular}{lrrrr}
\hline \multicolumn{5}{c}{ Table 05: Refined relationship between index returns and FFR changes (Pre financial crisis) } \\
\hline & US Market & UAE Market \\
\hline & Coefficients & P-value & Coefficients & P-value \\
Intercept $(\Pi)$ & $0.01 \%$ & $79.22 \%$ & $0.22 \%$ & $47.91 \%$ \\
Change in FFR $(\beta)$ & $0.07 \%$ & $53.95 \%$ & $-0.16 \%$ & $86.98 \%$ \\
Refined FFR $(\gamma)$ & $-0.07 \%$ & $57.20 \%$ & $-44.15 \%$ & $31.14 \%$ \\
\hline
\end{tabular}

From the model above, we notice that the relationship between the return of S\&P 500 and changes in the FFR is positive. If the FFR value increases, the return of S\&P 500 index increases by 0.00067 times the change in FFR. On the other hand, results support a negative relationship between the return of S\&P 500 and refined FFR where the return of S\&P 500 index decreases by 0.00067 . The $p$-values for the change in FFR and refined FFR were 0.539 and 0.572 . Both the values are found to be above the significant value at 0.05 inferring that the domestic market returns 
are not significantly impacted due to changes in FFR, whether positive or negative, during pre-financial crisis period. Further, it is noticeable that the relationship between the return of DFM and changes in the FFR is negative. If the FFR value increases, the return of DFM index will decrease by 0.0016 times the change in FFR. Findings also show a negative relationship between the return of DFM and refined FFR, where the return of DFM index will decrease by 0.4415 . The $p$-values for the change in FFR and refined FFR was 0.87 and 0.31 , indicating that changes in FFR and refined FFR are not associated with changes in the index returns, in the pre-financial crisis era.

\section{Post Financial Crisis}

Table 06: Refined relationship between index returns and FFR changes (Post financial crisis)

\begin{tabular}{|c|c|c|c|c|}
\hline & & Market & & UAE Market \\
\hline & Coefficients & P-value & Coefficients & P-value \\
\hline Intercept (П) & $0.07 \%$ & $1.96 \%$ & $0.15 \%$ & $8.98 \%$ \\
\hline Change in FFR $(\beta)$ & $0.80 \%$ & $0.04 \%$ & $2.83 \%$ & $0.00 \%$ \\
\hline Refined FFR $(\gamma)$ & $-0.81 \%$ & $0.14 \%$ & $-3.34 \%$ & $0.00 \%$ \\
\hline
\end{tabular}

Findings from Table 6 suggest that the relationship between the return of S\&P 500 and changes in the FFR is still positive. Furthermore, the relationship between the S\&P 500 return index and refined FFR remained negative. It can be observed that international market returns as indicated by the DFM index are affected due to change in FFR by 0.00798 times and are negatively related to the refined FFR by 0.0081 times. The small $p$-values for the change in FFR and refined FFR were 0.0003 and 0.0138 and are considered significant in affecting changes in index returns. Importantly, it is noticeable that the relationship between the return of DFM and changes in the FFR is positive after the financial crisis. If the FFR value increases, the return of DFM index will increase by 0.0283 times the change in FFR. On the other hand, findings support that the negative relationship between the return of DFM and refined FFR remained the same after the financial crisis. An increase in refined FFR will decrease the return of DFM index by 0.0334 times the refined FFR. The $\mathrm{R}^{2}$ value of $24.2 \%$ for the DFM index model is supported by the low $\mathrm{p}$-value for the change in FFR and refined FFR which were very low and below 0.05, suggesting changes in FFR, whether positive or negative tends to have a significant impact on changes in the UAE Index returns.

\subsection{Conclusion and policy implications}

The Federal Funds Rate has been trending downwards post the financial crisis of 2008, and had a significant positive effect on the UAE DFM market index compared to the US market. When analyzing the effect of policy reversals over the whole period, changes in FFR tend to have a positive significant effect for the domestic market (US). As part of robustness testing, the analysis was broken down further into pre and post financial crisis. In both the pre and post financial crisis time windows, changes in FFR appear not to have a significant impact on the indices returns. A further break down of the direction of the change in FFR, suggests no significant impact on both markets in the pre-crisis period. However, following Lehman Brothers bankruptcy, which is proxied as the start of the financial crisis, both the UAE and US index returns were significantly affected, when including the effect of a positive or negative change in FFR to the model. The effect is negative and more pronounced for the UAE index returns for the post financial crisis period. Overall, findings tend to support a change in the impact of changes in the Federal Funds Rate on market indices, whether US based or on international markets like UAE. This has policy implications, particularly for international financial markets, where regulatory bodies such as the Dubai Financial Services Authority (DFSA) and the Central Bank in UAE, have to closely monitor the impact of global macroeconomic variables such as interest rates, inflation and unemployment. This would align towards working and maintaining financial stability. More importantly, this raises a real need for policy makers who have pegged their currencies to US dollar, or any other major currency per say, to reassess whether following foreign interest rate policies set by the Federal Reserve Bank or the European Central Bank, have some significant consequences on their financial markets, while giving away the freedom of using independent monetary policies based on their own economic outlooks. The relationships between changes in monetary policy globally, like recently witnessed with the Federal Reserve Bank in the U.S. slowly reducing its Quantitative Easing (QE) while the European Central Bank starting to look at the possibility of QE cannot be ignored to avoid further financial markets' volatility sessions. Further research could accommodate the analysis of other major variables from other entities such as central banks, on other market indices in the region.

\section{References}

Bae SC, 1990. Interest rate changes and common stock returns of financial institutions: Revisited. Journal of Financial Research, 13: 71-79. http://dx.doi.org/10.1111/j.1475-6803.1990.tb00537.x 
Bernanke BS and Kuttner KN., 2005. What explains the stock market's reaction to Federal Reserve Policy? The Journal of Finance, 60: 1221-1257. doi: 10.1111/j.1540-6261.2005.00760.x http://dx.doi.org/10.1111/j.1540-6261.2005.00760.x

Craine R and Martin VL., 2008. International monetary policy surprise spillovers. Journal of International Economics, 75(1): 180-196. http://dx.doi.org/10.1016/j.jinteco.2007.06.005DFM (March 2014). Daily summary of DFM PJSC. Retrieved from: http://www.dfm.ae/pages/DailySummary.aspx?smb=DFM.

Economist (September 2013). The meaning of Lehman, Sep 26th 2013, Economist. Retrieved from: http://www.economist.com/blogs/freeexchange/2013/09/great-crash-4.

Effective Federal Funds Rate (2014). Effective Federal Funds Rate: Overview. Retrieved from: http://www.economiq.org/series/ff/

Elyasiani E and Mansur I., 2003. International spill over of risk and return among major banking institutions: $\mathrm{A}$ bivariate GARCH model. Journal of Accounting, Auditing \& Finance, 18(2): 303-330.

Faff RW and Howard PF., 1999. Interest rate risk of Australian financial sector companies in a period of regulatory change. Pacific-Basin Finance Journal, 7: 83-103. http://dx.doi.org/10.1016/S0927-538X(99)00002-5

Fama EF and French KR., 2004. The Capital Assets Pricing Model: theory and evidence. Journal of Economic Perspectives, 25-46. http://dx.doi.org/10.1257/0895330042162430

Flannery MJ and James CM., 1984. The effect of Interest rate changes on the common stock returns of financial institutions. Journal of Finance, 39: 1141-1153. http://dx.doi.org/10.1111/j.1540-6261.1984.tb03898.x

Garg K., 2008. The effect of changes in the Federal Funds Rate on stock Markets: A sector-wise analysis. Undergraduate Economic Review, 4(1).

Grouard MH., Levy S., and Lubochinsky C., 2003. Stock market volatility: From empirical data and their interpretation. FSR, Banque de France, 57-74.

Hegwood N and Tuttle MH., 2013. Did the mortgage interest rate fail to respond to Federal Funds Rate Changes: Testing for a short-run break, 2002-2005. Journal of Money Banking, and Finance, 1(1): 13-26.

Koba M., 2012. Federal Funds Rate: CNBC explains. CNBC. Retrieved from: http://www.cnbc.com/id/46071997.

Madura J and Zarruk ER., 1995. Bank exposure to interest rate risk: a global perspective. Journal of Financial Research, 18, 1-13. http://dx.doi.org/10.1111/j.1475-6803.1995.tb00207.

Mahn K., 2014. Fed On Target To Raise Interest Rates In The Spring Of 2015. Seeking Alpha. Retrieved from: http://seekingalpha.com/article/2111443-fed-on-target-to-raise-interest-rates-in-the-spring-of-2015.

MSCI (May 2012). How to calculate returns from daily closing prices in Excel. Retrieved http://www.msci.com/eqb/methodology/meth_docs/MSCI_May12_IndexCalcMethodology.pdf.

Newyork Fed. (April 2014). Federal Reserve Bank of New York, Retrieved from: http://www.newyorkfed.org/markets/omo/dmm/historical/fedfunds/ff.cfm.

Sweeney RJ and Warga AD., 1986. The pricing of interest rate risk: Evidence from the stock market. Journal of Finance, 14: 393-410. http://dx.doi.org/10.1111/j.1540-6261.1986.tb05044.x

Tai CS., 2000. Time varying market, interest rate, and exchange rate risk premia in the US commercial bank stock returns. Journal of Multinational Financial Management, 10: 397-420. http://dx.doi.org/10.1016/S1042444X(00)00031-1

Taibbi M., 2010. Griftopia: bubble machines, vampire squids, and the long con that is breaking America. Spiegel \& Grau, 35-36. ISBN 978-0-385-52995-2.

Thornton DL, 2000. The relationship between the federal funds rate and the Fed's federal funds rate target: Is it open market or open mouth operations? Working Papers 1999-022, Federal Reserve Bank of St. Louis.

Yahoo Finance (March 2014). Historical data of ^GSPC. Retrieved from: http://finance.yahoo.com/echarts?s=\%5EGSPC+Interactive\#symbol=\%5EGSPC;range=

Yin H and Yang J., 2013. The sensitivity of non-U.S. bank stock returns to changes of monetary policy. Journal of Applied Finance \& Banking, 3(6): 25-43. 